\title{
BENCANA DALAM KONTEKS SPIRITUALITAS ISLAM
}

\author{
Oleh: \\ Ahmad 1 \\ Email: ahjelly@gmail.com
}

\begin{abstract}
Natural disasters are extraordinary events that occur in the universe. Starting from floods, landslides, hurricanes, volcanic eruptions, earthquakes and tsunamis. Scientifically, natural disasters occur because of an imbalance in the universe. While according to the religious perspective, disasters occur due to the actions of humans who commit many sins. Natural disasters can occur as a form of examination (mihnah), reply ('iqob), disaster (bala') or also as a torment (doom) the wrath of the Creator on his servant. In the Qur'an and Hadith, the disaster that befalls humanity is more caused by sinful acts and lawlessness. The former people got the punishment because they did not believe in God and denied the messengers who had been sent down to them and did arrogant and dhalim. However, in today's context, humans do not ensure that natural disasters that afflict a region (clan) are surely doom. Likewise, it cannot be ascertained that humans who are victims of disasters are disobedient humans. This is because those who are also victims include pious people.
\end{abstract}

Key words: disaster, al-Qur'an, Hadith

\section{Pendahuluan}

Indonesia negeri bencana, demikian pameo yang muncul seiring dengan banyaknya bencana menerpa bumi pertiwi. Saat musim penghujan: banjir, longsor, badai silih berganti menerjang. Sementara saat kemarau: musibah kebakaran, kekeringan, hingga kelaparan ikut sering menyapa. Tahun 2018, Indonesia bertubi-tubi dilanda bencana besar. Gempa Lombok melanda pertama kali tanggal 29 Juli 2018 bermagnitudo 6.4. Gempa ini seakan tak pernah berhenti. Gempa susulan 524 kali secara terus-menerus seakan melanda. Sebanyak 1.454 rumah, 7 Fasilitas pendidikan, 22 tempat ibadah, 5 unit kesehatan, 37 kios dan 1 jembatan rusak. Pada 5 Agustus

${ }^{1}$ Dosen Prodi Hukum Pidana Islam STAI Syaichona Moh. Cholil Bangkalan 
2018 kembali terjadi gempa berkekuatan magnitude 7 yang semakin meluluhlantahkan bumi Sasak. Akibatnya 390 orang tewas, 1447 luka-luka, 67.875 rumah dan 468 sekolah rusak, serta 352.793 orang harus mengungsi ${ }^{2}$. Belum selesai pemulihan gempa Lombok, bumi Nusantara kembali diterjang bencana yang cukup mengerikan. Pada tanggal 29 September 2018, gempa berskala 7.4 Mw melanda Palu, yang diikuti tsunami serta likuifaksi. Dampak gempa Palu jauh lebih mengerikan daripada gempa Lombok. Hal ini disebabkan karena bencana gempa tidak hanya datang sendirian, gempa diikuti oleh tsunami serta likuifaksi. Gempa palu telah meluluhlantahkan ribuan rumah, diikuti gelombang tsunami memberangus segala hal yang ditemui, serta likuifaksi yang ikut menenggelamkan beberapa desa. Lebih dari 2.000 orang dilaporkan meninggal. Ratusan orang dilaporkan masih hilang, ribuan rumah roboh dan hilang ditelan bumi ${ }^{3}$.

Menurut Mashdar Hilmy bencana yang terjadi di bumi Nusantara tidak hanya terjadi pada dimensi alam, namun juga terjadi dalam dimensi sosial kemasyarakatan yaitu bencana kebohongan. Menurut Mashdar, bahwa media sosial telah membawa dampak perubahan besar dalam interaksi sosial kemasyarakatan bangsa Indonesia. Media sosial mempermudah dan mempercepat terjadinya bencana kebohongan. Bencana alam telah menciptakan kerusakan yang besar, namun bencana kebohongan justru menciptakan kerusakan yang lebih besar, termasuk pemulihannya4.

Kehidupan sosial kemasyarakatan akhir-akhir ini terlalu banyak diwarnai oleh berita bohong (hoax). Diakui atau tidak, bencana kebohongan ini -sebagaimana diintrodusir oleh Mashdar Hilmy- diproduksi dari kepentingan politik. Friksi dinamika politik Indonesia terjadi begitu tajam setidaknya dimulai dari proses pemilihan pilkada DKI Jakarta.

Jika ditelisik lebih jauh -meminjam alur pikir Masdhar Hilmy, dengan demikian- bencana di bumi Nusantara tidak hanya terjadi dalam

${ }^{2}$ www.wikipedia.Org. diakses pada tanggal 13 Oktober 2018.

${ }^{3}$ www.wikipedia.Org. diakses pada tanggal 13 Oktober 2018.

4 Mashdar Hilmy dalam Harian Kompas 13 Oktober 2018. Negeri di antara Dua Bencana 
ranah alam dan sosial kemasyarakatan. Namun juga terjadi dalam dimensi politik, ekonomi, bahkan agama. Bencana politik negeri ini terjadi pada perilaku korupsi yang merajalela. Korupsi tidak lagi menjadi sebuah kejahatan luar biasa sebagaimana bunyi undang-undang, sebaliknya korupsi justru menjadi kejahatan biasa dan dianggap biasa. Perilaku suapmenyuap, potongan, fee, manipulasi hingga mark-up anggaran menjadi berita setiap hari ${ }^{5}$. Yang lebih mengerikan lagi, korupsi tidak hanya terjadi di kalangan para elit, rakyat jelatapun juga menikmati cipratan-cipratan aliran korupsi. Setidaknya yang paling mudah dilihat adalah bentuk money politic saat menjelang pemilihan. Sembako, uang hingga kaos menjadi pemandangan yang lazim saat pemilihan. Money politic ini tidak hanya terjadi dalam pemilihan presiden, DPR/DPRD dan DPD, gubernur, bupati/wali kota, namun juga terjadi hingga pemilihan kepala desa dan ketua RT.

Bencana dalam dimensi ekonomi terjadi dengan adanya krisis ekonomi. Krisis ekonomi tersebut setidaknya ditandai dengan adanya ketidakstabilan ekonomi, melambungnya harga-harga kebutuhan, meroketnya nilai tukar, kekhawatiran atas jumlah utang, hingga kekhawatiran atas ketahanan ekonomi nasional. Beberapa indikator tersebut harus diwaspadai sebagai awal atas permulaan bencana krisis ekonomi yang lebih mengerikan. Jika tidak, maka dampak dari krisis ekonomi benar-benar akan menyusahkan ekonomi Indonesia.

Sementara bencana di bidang agama setidaknya dapat dipetakan dari banyaknya tokoh dan penganut agama yang mengabaikan ajaran-ajaran agamanya. Banyak para pemuka agama yang seharusnya menjadi penuntun umat, justru mempermainkan agama. Banyak orang yang memahami ajaran agama namun tidak mengamalkannya.

\section{Pembahasan}

\section{Musibah}

${ }^{5}$ Komisi Pemberantasan Korupsi telah melakukan banyak penangkapan para Pejabat yang terlibat Korupsi baik Pejabat Eksekutif, Legislatif dan Yudikatif. Tercatat 321 Pejabat Eksekutif, mulai dari Menteri, Gubernur, Bupati/Walikota, Pejabat Eselon I, II dan III, 205 Anggota DPR/DPRD, dan 37 Penegak Hukum mulai dari Hakim, Jaksa, Polisi dan Pengacara telah ditangkap KPK. Sumber Data KPK. www.kpk.go.id. diakses 26 Oktober 2018. 
Musibah berasal dari akar kata sho wa ba صوب) yang berarti turun. Dari akar kata ini juga lahir kata showab (benar). Musibah dengan demikian adalah segala sesuatu yang menimpa/terjadi pada diri seorang manusia, buruk ataupun baik. Hal ini sesuai dengan firman Allah:

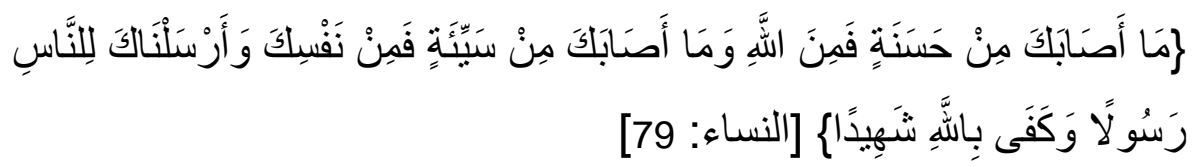

"Apa saja nikmat yang kamu peroleh adalah dari Allah, dan apa saja bencana yang menimpamu, maka dari kesalahan dirimu sendiri. Kami mengutusmu menjadi Rasul kepada segenap manusia. Dan cukuplah Allah menjadi saksi. (an-Nisa': 79).

Kata musibah sendiri terulang sebanyak 10 kali dalam al-Qur'an; yaitu: al-Baqoroh: 156, al-Imron: 165, an-Nisa': 62, an-Nisa': 72, al-Ma'idah: 106, at-Taubah: 50, al-Qoshos: 47, as-Syura: 30, al-Hadid: 22, at-Tagobun: 11)

\section{Bala'}

Bala' berasal dari akar akar ba laa (بلى) yang berarti ujian. Ujian dapat berbentuk ujian baik dan buruk. Allah berfirman:

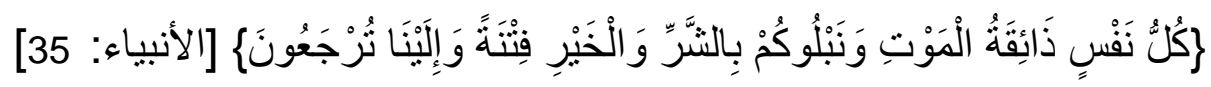

"Tiap-tiap berjiwa akan merasakan mati. Kami akan menguji kamu dengan keburukan dan kebaikan sebagai cobaan (yang sebenar-benarnya). Dan hanya kepada Kamilah kamu dikembalikan". (QS al-Anbiya: 35)

Dalam sebuah Hadits ditemukan permohonan Nabi agar diberikan ujian yang baik.

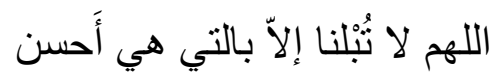


"Ya Allah, janganlah Engkau uji kami kecuali dengan ujian yang paling baik".

Dalam pengertian yang lain, bala' berarti nikmat. Makna ini ditemukan dalam sebuah Hadits:

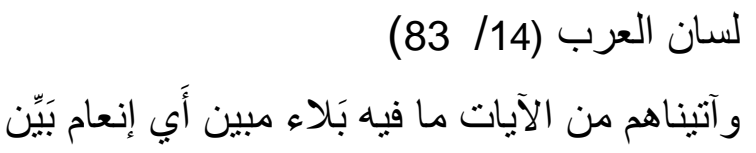

Pengertian ini juga ditemukan dalam sebuah Hadits:
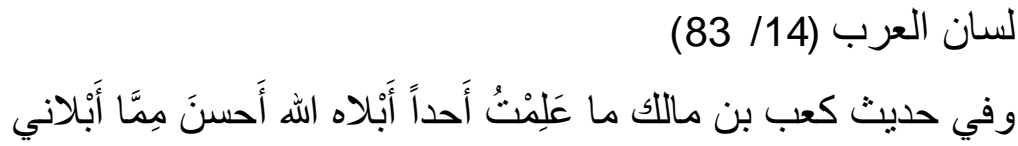

"Tidak ada seorangpun yang diuji oleh Allah dengan ujian yang lebih baik daripada ujian yang Allah berikan kepadaku".

Kata bala' terulang sebanyak 5 kali dalam al-Qur'an yaitu alBaqoroh:49, al-A'rof: 141, al-Anfal: 17, Ibrohim: 6, ad-Dukhon: 33).

\section{‘Iqab}

'Iqab berasal dari akar kata 'aqaba (عقب) yang berarti sesudah, tumit atau di belakang. Dari akar kata inilah lalu terambil kata 'iqab yang berarti siksaan. Kata 'iqab terulang sebanyak 4 kali dalam al-Qur'an yaitu: arRa'du: 32, Shood: 14, Ghofir: 5, Fushshilat: 43. Salah satu contohnya isi surat:

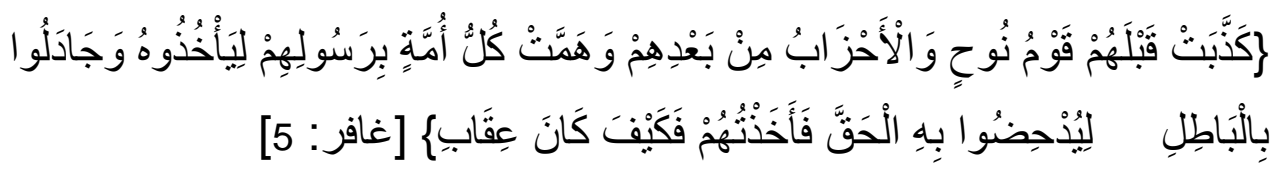

"Sebelum mereka, kaum Nuh dan golongan-golongan yang bersekutu sesudah mereka telah mendustakan (rasul) dan tiap-tiap umat telah 
merencanakan makar terhadap rasul mereka untuk menawannya dan mereka membantah dengan (alasan) yang batil untuk melenyapkan kebenaran dengan yang batil itu; karena itu aku azab mereka. Maka betapa pedihnya azab-Ku".

Jika memperhatikan 4 ayat di atas, kata 'iqob selalu disandingkan dengan risalah para rasul. Bahwa umat yang mendustakan para rasul akan mendapatkan 'iqob.

\section{Mihnah}

Mihnah terambil dari akar kata mahana (محن) yang berarti ujian.
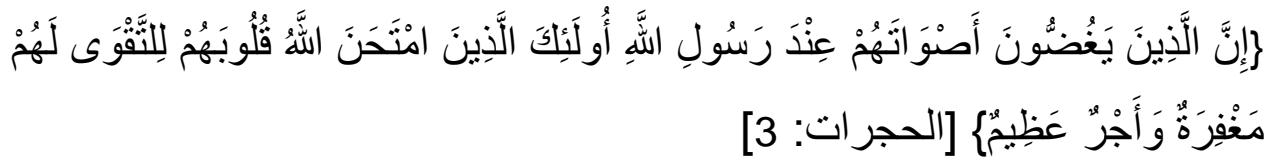

"Sesungguhnya orang yang merendahkan suaranya di sisi Rasulullah mereka itulah orang-orang yang telah diuji hati mereka oleh Allah untuk bertakwa. Bagi mereka ampunan dan pahala yang besar.

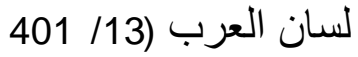

أَن رسول الله صلى الله عليه و سلم قال الَََلْى ثناثة رجل مؤمن جاهَدَ بنفسه وماله

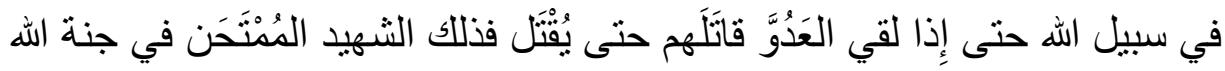
تحت عرشه

“Orang yang terbunuh terbagi menjadi tiga; (salah satunya yaitu) seorang mukin yang berjihad di jalan Allah dengan jiwa dan harta, lalu dia bertemu musuh, berperang lalu terbunuh. Dialah seorang Syahid yang teruji. Dia (nanti) akan berada di surga di bawah Arsy Allah". 


\section{Azab}

Azab terambil dari akar kata 'adzaba (عذب) yang berarti air tawar. Dari kata ini lalu muncul azab (عذاب) yang berarti hukuman dan siksaan. Dalam banyak pemakaian, kata azab selalu disandingkan dengan perbuatan yang berdampak pada adanya hukuman atau siksaan atas perbuatan tersebut. Sebagai contoh:

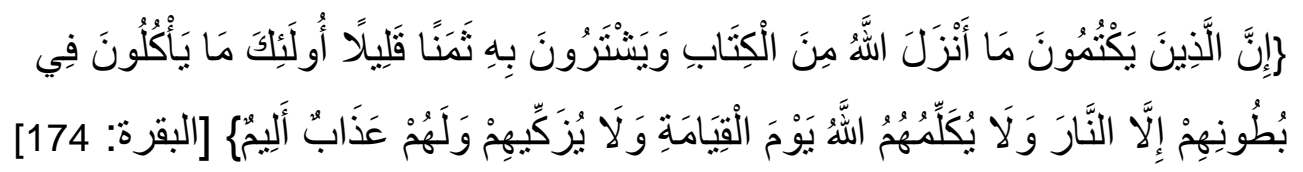

"Sesungguhnya orang-orang yang menyembunyikan apa yang telah diturunkan Allah, yaitu kitab dan menjualnya dengan harga yang sedikit (murah), mereka itu sebenarnya tidak memakan (tidak menelan) ke dalam perutnya melainkan api, dan Allah tidak akan berbicara kepada mereka pada hari kiamat dan tidak mensucikan mereka dan bagi mereka siksa yang amat pedih".

Kata azab sering disandingkan dengan kata 'adhim, aliim, muhiin, annar, al-akhirah. Kata azab banyak dijumpai dalam banyak surat dalam alQur'an. Setiap peristiwa besar kisah umat-umat terdahulu sering diakhiri dengan adanya azab dari Allah. Al-Qur'an menyebutkan bahwa azab yang menimpa mereka selalu disebabkan oleh kedurhakaan, kekufuran, dan kedholiman yang mereka lalukan.

\section{Azab Umat-Umat Terdahulu}

\section{Azab Umat Nabi Hud (Kaum 'Ad)}

Nabi Hud diutus untuk kaum 'Ad. Mereka mendustakan kenabian Nabi Hud. Allah lalu mendatangkan angin yang dahsyat disertai dengan bunyi guruh yang menggelegar yang membinasakan mereka ${ }^{6}$. (QS Attaubah: 70, Alqamar: 18, Fushshilat: 13, Annajm: 50, Qaaf: 13).

6 Dr. Muhammad Mahmud Hijaziy. Tafsir al-Wadhih. Maktabah Syamilah (Kitab Digital) . Juz 3 hlm 329. 


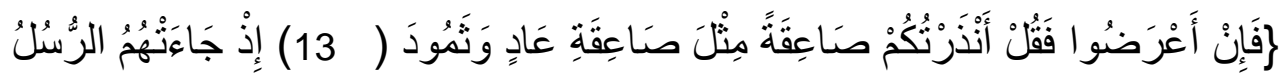

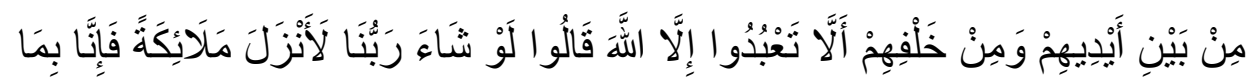

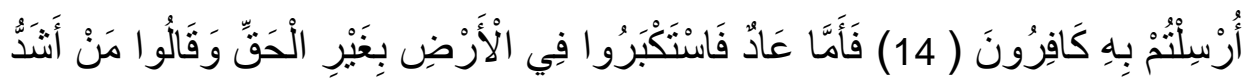

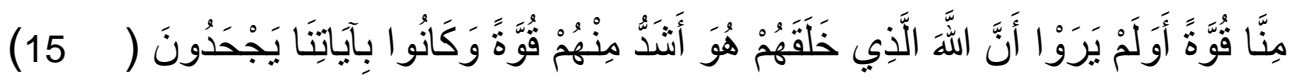

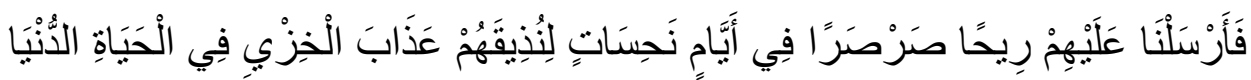

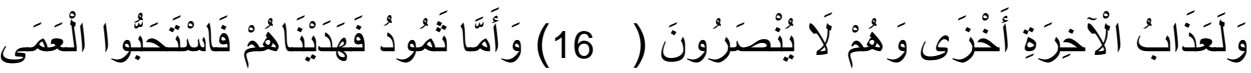

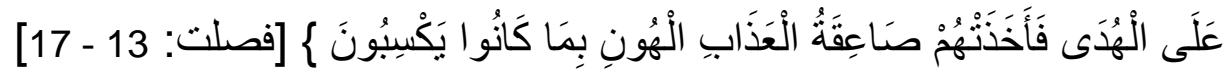

\section{Umat Nabi Saleh (Kaum Tsamud)}

Nabi Saleh diutus oleh Allah kepada kaum Tsamud. Kaum Tsamud adalah kaum yang sangat pandai membuat ukiran batu, hingga ukiran yang dihasilkan bisa menyerupai bentuk aslinya. Mereka mengukir bebatuan dan tinggal di dalamnya7. Mereka lalu sombong dengan kemampuan ini. Nabi Saleh diberi sebuah mukjizat mampu menghidupkan seekor unta betina keluar dari celah batu. Namun, mereka membunuh unta betina tersebut sehingga Allah menimpakan azab kepada mereka (QS Alhijr: 80, Huud: 68, Qaaf: 12).

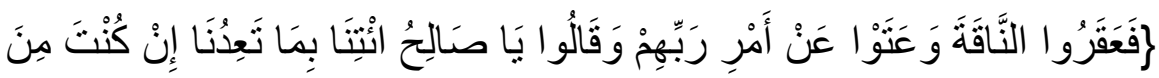

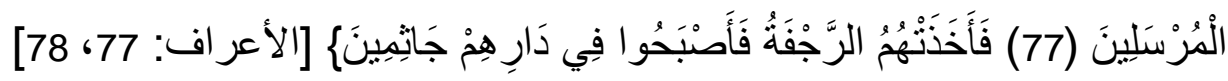

"Kemudian mereka menyembelih unta betina itu, dan mereka berlaku angkuh terhadap perintah Tuhan. Dan mereka berkata "Hai Saleh datangkanlah apa yang kamu ancamkan itu kepada kami, jika (betul) kamu termasuk orang-orang yang yang diutus (Allah). Karena itu mereka ditimpa gempa, maka jadilah mereka mayat-mayat yang bergelimpangan di tempat tinggal mereka".

7 Dr. Muhammad Sayid Thanthowi. Tafsir al-Wasiith li al-Qur'an al-Karim. Maktabah Syamilah (Kitab Digital) . Juz 5 hlm 308. 


\section{Azab Umat Nabi Nuh}

Nabi Nuh berdakwah selama 950 tahun. Dalam waktu yang cukup lama ini, umat yang beriman kepada Nabi hanya sekirat 80 orang8. Kebanyakan kaumnya, lebih banyak yang mendustakannya. Allah lalu memerintahkan Nabi Nuh membuat perahu di atas bukit pada musim kemarau. Melihat hal ini, umat Nabi Nuh, malah menertawakan dan mengolok-oloknya. Allah lalu mengadzab mereka dengan mendatangkan banjir yang besar, kemudian menenggelamkan mereka yang ingkar, termasuk anak dan istri Nabi Nuh. Kisah Nabi Nuh banyak tercantum dalam al-Qur'an. (Hud: 40-45, Al-Ankabut : 14).

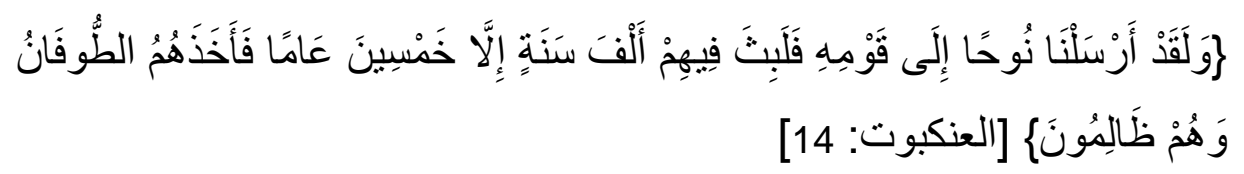

"Sesungguhnya Kami telah mengutus Nuh kepada kaumnya, maka ia tinggal di antara mereka seribu tahun kurang lima puluh tahun. Maka mereka ditimpa banjir besar dan mereka adalah orang-orang yang dholim".

\section{Azab Umat Nabi Luth}

Nabi Luth diutus kepada kaum Sodom9. Kaum Sodom, terkenal dengan perbuatan menyimpang. Mereka tidak melakukan perkawinan sebagaimana mestinya, laki-perempuan. Mereka menikah dengan pasangan sesama jenis (homoseksual dan lesbian). Kendati sudah diberi peringatan, mereka tak mau bertobat. Allah akhirnya memberikan azab kepada mereka berupa gempa bumi yang dahsyat disertai angin kencang

8 Ulama' berbeda pendapat tentang jumlah pasti pengikut Nabi Nuh. Sebuah pendapat mengatakan 80 orang, atau 80 orang laki-laki dan perempuan, atau 83 orang. Lihat Abu Hayyan Muhammad bin Yusuf. Tafsir al-Bahr al-Muhiit. Maktabah Syamilah (Kitab Digital) . Juz 6 hlm 404.

9 Fakhruddin Ar-Rozi menyebutkan dalam kitab tafsirnya, Tafsir ar-Rozi bahwa kota Sodom terdiri dari 5 desa/daerah. Allah membinasakan empat desa dan menyisakan satu desa. Lihat Abu Abdullah Muhammad Fakhruddin ar-Rozi. Tafsir arRozi. Maktabah Syamilah (Kitab Digital) . Juz 11 hlm 423. 
dan hujan batu sehingga hancurlah rumah-rumah mereka. Dan, kaum Nabi Luth ini akhirnya tertimbun di bawah reruntuhan rumah mereka sendiri (QS al-Syu'araa: 160, an-Naml: 54, al-Hijr: 67, al-Furqan: 38, Qaf: 12).

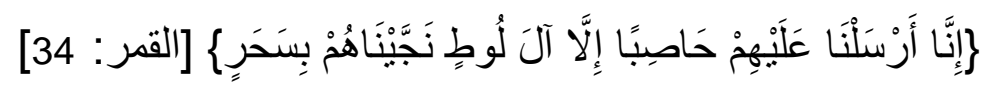

"Sesungguhnya Kami telah menghembuskan kepada mereka angin yang membawa batu-batu (yang menimpa mereka) kecuali keluarga Luth. Mereka kami selamatkan sebelum fajar menyingsing".

\section{Azab Umat Nabi Syu'aib}

Nabi Syu'aib diutuskan kepada kaum Madyan. Kaum Madyan adalah kaum yang pintar dalam berniaga. Perniagaan kaum Madyan tumbuh dan berkembang. Kaum Madyan ini dihancurkan oleh Allah karena mereka suka melakukan penipuan dan kecurangan dalam perdagangan ${ }^{10}$. Bila membeli, mereka minta dilebihkan dan bila menjual selalu mengurangi. Allah pun mengazab mereka berupa hawa panas yang teramat sangat. Kendati mereka berlindung di tempat yang teduh, hal itu tak mampu melepaskan rasa panas. Akhirnya, mereka binasa (QS at-Taubah: 70, al-Hijr: 78, Thaaha: 40, dan al-Hajj: 44).

Selain kepada kaum Madyan, Nabi Syu'aib juga diutus kepada penduduk Aykah. Mereka mempunyai kebun-kebun yang sangat lebat, yang disebut pohon Dawm (الدوم). Mereka diazab dengan (gelombang) panas selama tujuh hari, hingga mereka tidak menemukan tempat berteduh. Lalu Allah mendatangkan awan sehingga mereka berteduh di bawahnya, hingga kemudian membinasakan mereka11. (QS al-Hijr: 78, al-Syu'araa: 176, Shaad: 13, Qaaf: 14).

10 Lihat Muhammad bin Ahmad Abu Abdilla al-Qurtubiy. Tafsir al-Qurtubiy. Maktabah Syamilah (Kitab Digital) . Juz 9 hlm 84.

11 Lihat Abu Jakfar Muhammad Bin Jarir ath-Thobary. tafsir ath-Thobari. Maktabah Syamilah (Kitab Digital) . Juz 14 hlm 100. 


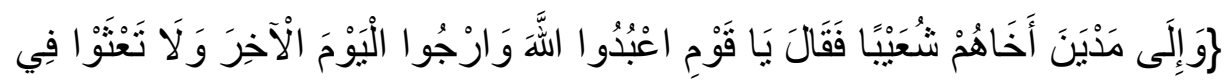

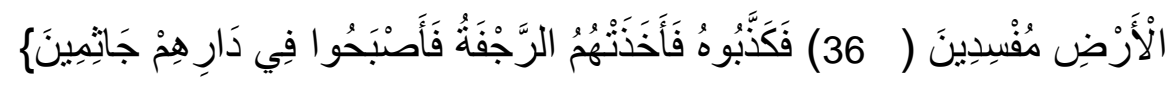

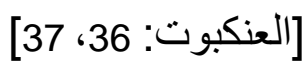

"Dan (kami telah mengutus) kepada penduduk Madyan, saudara mereka Syu'aib, maka ia berkata: "Hai kaumku, sembahlah olehmu Allah, harapkanlah (pahala) hari akhirnya, dan jangan kamu berkeliaran di muka bumi berbuat kemaksiatan. Maka mereka mendustakan Syu'aib, lalu mereka ditimpa gempa yang dahsyat, dan jadilah mereka mayat-mayat yang bergelimpangan di tempat-tempat tinggal mereka".

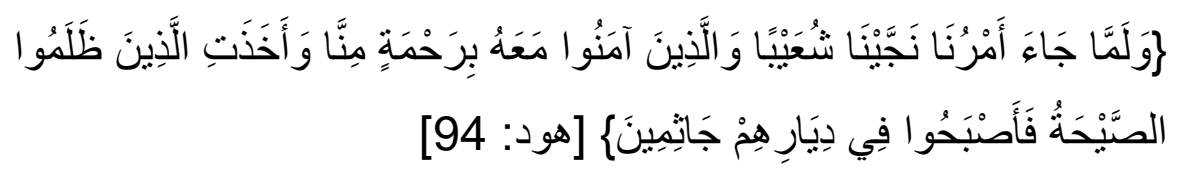

"Dan tatkala datang adzab Kami, Kami selamatkan Syu'aib dan orangorang yang beriman bersama-sama dengan dia dengan rahmat dari Kami, dan orang-orang yang dholim dibinasakan oleh suara yang mengguntur, lalu jadilah mereka mati bergelimpangan di rumahnya".

\section{Azab Umat Nabi Musa}

Fir'aun

Nabi Musa diutus kepada kaum Bani Israil. Kaum Bani Israil sering ditindas oleh Fir'aun. Nabi Musa adalah anak angkat Fir'aun yang ditemukan terhanyut di Sungai Nil. Allah mengutus Nabi Musa dan Harun untuk memperingatkan Firaun akan azab Allah. Fir'aun mempunyai kekuasaan yang sangat besar. Namun, Firaun memerintah dengan dholim dan malah mengaku dirinya sebagai Tuhan. Fir'aun dan bala tentaranya tewas di Laut Merah saat melakukan pengejaran kepada Nabi Musa dan para pengikutnya12. (QS. al-Baqarah: 50 dan Yunus: 92).

12 Lihat Muhammad Aly As-Shobuni. Shofwah at-Tafsir li ash-Shobuni. Maktabah Syamilah (Kitab Digital) . Juz 12 hlm 12. 


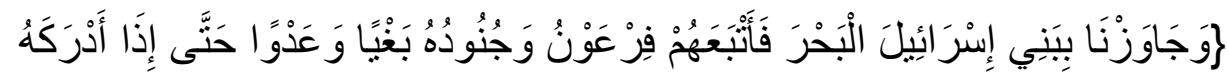

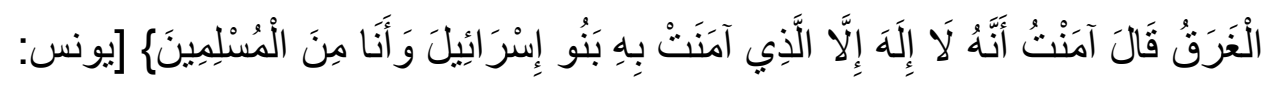

"Dan Kami memungkinkan Bani Israil, melintasi laut, lalu mereka diikuti oleh Fir'aun dan bala tentaranya, karena hendak menganiaya dan menindas (mereka). Hingga saat Fir'aun telah hampir tenggelam berkatalah dia: "Saya percaya tidak ada Tuhan melainkan Tuhan yang dipercayai oleh Bani Israil, dan saya termasuk orang-orang yang berserah diri (kepada Allah)".

\section{Qarun}

Qarun disebutkan sebagai salah satu keluarga dari Nabi Musa. Qarun adalah sepupu Nabi Musa. Pada mulanya, Qarun adalah seorang yang sangat miskin. Suatu hari, Qarun meminta kepada Nabi Musa agar dia diberi kekayaan oleh Allah. Singkat cerita, Allah lalu mengabulkan doa Nabi Musa dan menjadikan Qarun sebagai orang yang kaya raya. Kekayaannya disimpan dalam banyak ribuan gedung penyimpanan harta, hingga kunci-kuncinya gedungnya harus dipikul oleh puluhan orang. Namun Qarun durhaka dan kufur atas nikmat yang Allah berikan. Allah lalu mengazab Qarun dengan menenggelamkannya ke dalam bumi beserta seluruh kekayaannya. (al-Qoshos, al-Ankabut:39-40, dan al-Mukmin).

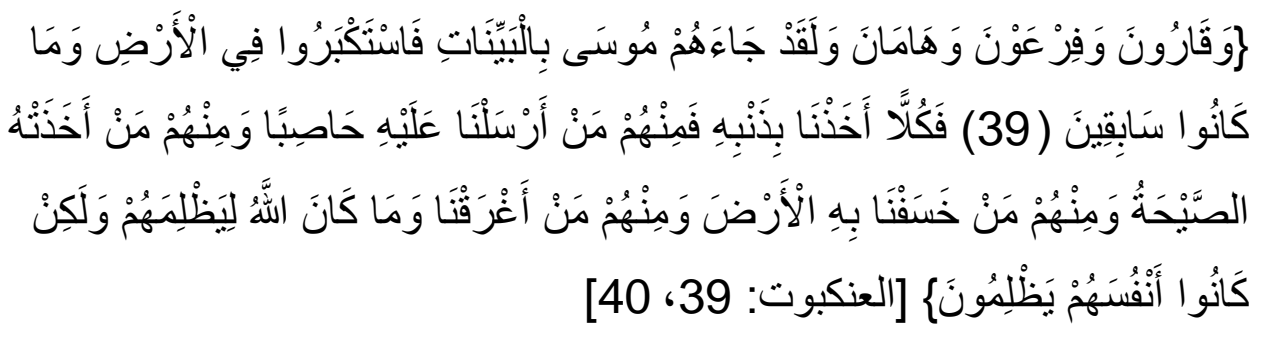

“Dan Qarun, Fir'aun dan Haman. Dan sesungguhnya telah datang kepada mereka Musa dengan (membawa bukti-bukti) keteranganketerangan yang nyata. Akan tetapi mereka berlaku sombong di muka 
bumi, dan tiadalah mereka orang-orang yang luput (dari kehancuran itu). Maka masing-masing (mereka itu) Kami siksa disebabkan dosanya. Maka di antara mereka ada yang Kami timpakan kepadanya hujan batu kerikil dan di antara mereka ada yang ditimpa suara keras yang mengguntur, dan di antara mereka ada yang kami benamkan ke dalam bumi, dan di antara mereka ada yang kami tenggelamkan, dan Allah sekali-kali tidak hendak menganiaya mereka, akan tetapi merekalah yang menganiaya diri mereka sendiri".

\section{Ibroh (Pelajaran) Kisah Umat Terdahulu}

Al-Qur'an, bahwa dalam kisah-kisah umat terdahulu terdapat peringatan dan pelajaran yang bisa dipetik bagi orang yang mau berpikir. Hal ini sebagaimana firman Allah dalam Surat Yusuf: 111.

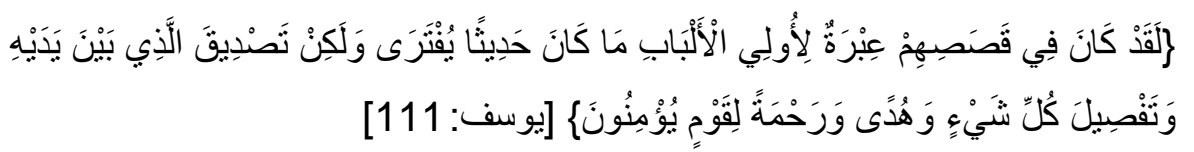

"Sesungguhnya pada kisah-kisah mereka itu terdapat pengajaran bagi orang-orang yang mempunyai akal. Al-Qur'an bukanlah cerita yang dibuat-buat, akan tetapi membenarkan (kitab-kitab) yang sebelumnya dan menjelaskan segala sesuatu, dan sebagai petunjuk dan rahmat bagi kaum yang beriman".

Demikian juga, Nabi juga telah menegaskan bahwa setiap perbuatan maksiat, kekufuran, durhaka, dan kedholiman serta perbuatan jahat lainnya akan berdampak pada balasan ('iqob) yang akan diterima. Balasan tersebut ada yang disegerakan di dunia dan ada pula yang ditunda di akhirat nanti sebagai balasan di neraka.

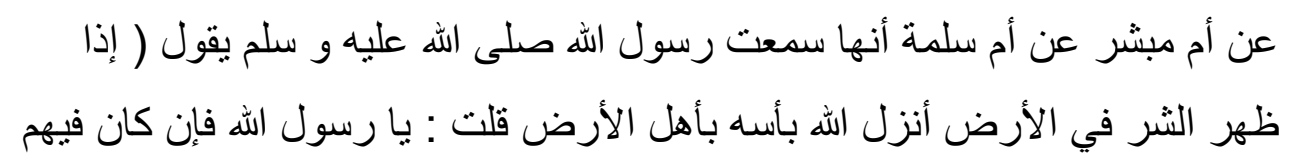


قوم صالحون ؟ قال : ( نعم وإن كان فيهم قوم صالحون بصيبهم ما أصاب الناس ثم يرجعون إلى رحمة الله ومغفرته )

"Apabila kejelekan telah tampak (merajalela) di atas bumi, maka Allah akan menurunkan bencana. Saya (sahabat) bertanya: "bagaimana dengan orang-orang shaleh?" Nabi menjawab "ya, (sama) Allah menimpakan (azab) kepada mereka sebagaimana menimpa orang-orang, lalu mereka (diharapkan) kembali pada rahmat dan ampunan Allah"13.

Al-Qur'an juga menegaskan bahwa kerusakan di atas bumi terjadi karena disebabkan oleh perbuatan manusia.

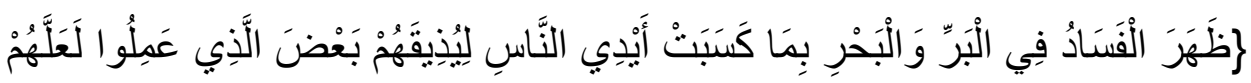

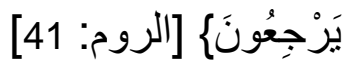

"Telah nampak kerusakan di atas bumi, baik di darat atau lautan disebabkan perbuatan tangan-tangan manusia, supaya Allah merasakan kepada mereka sebagian dari (akibat) perbuatan mereka, agar mereka kembali (ke jalan yang benar)".

موسو عة فقه الابتلاء (1/ 233)

ما أصاب الناس من عقوبات هو بسبب ذنوبهر قال تعالى :وَمَا أَصَابَكُمُ مِّن مُّصِيَيَةٍ

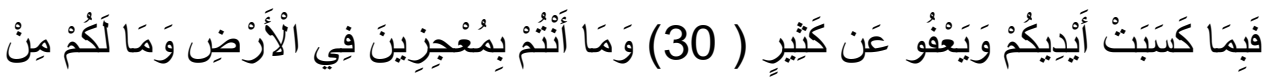

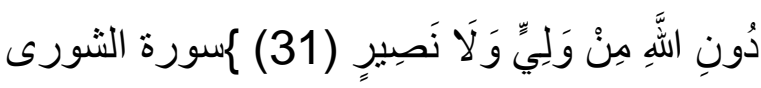

13 Lihat Sulaiman bin Ahmad Abu al-Qosim ath-Thobroniy. Mu'jam al-Kabir li ath-Thobroniy. Maktabah Syamilah (Kitab Digital) . Juz 23 hlm 377. 


\section{Penolak Azab}

Sebagai bentuk preventif, al-Qur'an juga memberikan cara agar manusia bisa terhindar dari azab yaitu dengan memperbanyak minta ampun kepada Allah.

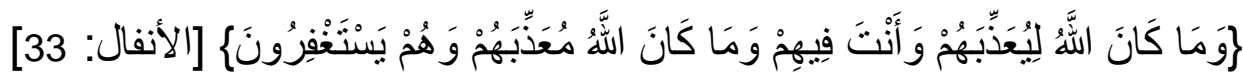

"Dan Allah sekali-kali tidak akan mengazab mereka, sedang kamu berada di antara mereka. Dan tidaklah (murka) Allah akan mengazab mereka sedang mereka meminta ampun".

Demikian, Nabi juga menjelaskan bahwa memperbanyak shodaqoh dalam menghindarkan diri dari bala'.

$$
\text { ألصدقة تدفع البلاء }
$$

Syaikh Abd Rouf al-Munawi dalam kitab Faidul Qodir menjelaskan bahwa yang dimaksud shodaqah disini bukan hanya shadaqah dengan harta melainkan shodaqoh dengan semua perbuatan ketaatan kepada Allah ${ }^{14}$.

Apakah bencana yang terjadi merupakan azab, ujian, ataukah teguran dari Allah? Pertanyaan ini adalah pertanyaan yang hanya Allahlah yang bisa menjawabnya. Manusia tidak mempunyai kemampuan untuk menentukan dan menjawab apakah bencana alam yang terjadi adalah azab, ujian, atau hanya teguran dari Allah. Namun yang jelas, alQur'an Surat ar-Rum: 41 ataupun Hadits Nabi riawayat Ummu Salamah, menyatakan bahwa bencana alam yang ditimpakan oleh Allah bertujuan agar manusia kembali lagi.

Abu Hamid al-Ghazali menulis bahwa seorang hendaknya melakukan introspeksi diri terhadap dirinya sendiri sebelum menilai orang. Keselamatan seseorang terletak pada proses penyucian jati dirinya sendiri, sehingga seorang hamba bisa selamat baik di dunia atau di akhirat. Dalam kepentingan muhasabah ini, al-Ghozali menetapkan lima proses yang harus dihadapi yaitu: musyarothoh (مشارطة) yaitu seseorang harus

14 Syaikh Abd. Rouf al-Munawi. Faidhul Qodir. Maktabah Syamilah (Kitab Digital) . Juz 5 hlm 21. 
menetapkan syarat-syarat meraih keselamatan, lalu muroqobah (مر اقبة) yaitu merasa bahwa dirinya jauh dari Allah sehingga harus mendekatkan diri kepada Allah, lalu melakukan muhasabah (محاسبة) yaitu menghitunghitung (introspeksi diri) terhadap kesalahan serta dosa-dosa yang telah ia lakukan, lalu kemudian melakukan mu'aqobah (معاقبة) bahwa ia merasa perbuatan baik yang telah dilakukannya sangatlah sedikit, sementara dosadosa yang ia lakukan sangat banyak sehingga pantas untuk mendapatkan siksaan $^{15}$.

\section{Simpulan}

Pada dasarnya, semua musibah yang menimpa umat manusia terjadi disebabkan karena perbuatan manusia itu sendiri, baik ataupun buruk. Dalam konteks Islam, bencana alam yang terjadi juga merupakan bagian dari akibat perbuatan manusia, baik langsung ataupun tidak langsung. Namun demikian, manusia yang menjadi korban bencana alam tidak dapat dipastikan bahwa dia telah diazab oleh Allah, mengingat bahwa orangorang sholehpun dapat juga terkena bencana sebagai bagian dari azab yang telah menimpa kaumnya. Oleh karena itu, manusia diharapkan selalu melakukan muhasabah diri atas segala kesalahan dan dosa yang telah dilakukannya. Hal ini agar dapat menghindarkan diri dari turunnya bencana dan malapetaka.

15 Abu Hamid al-Ghozali. Ihya' Ulumi ad-Din. Maktabah Syamilah (Kitab Digital) . Juz 3 hlm 450. 


\section{Daftar Pustaka}

Al-Ghozali, Abu Hamid. Ihya' Ulumi ad-Din. Maktabah Syamilah (Kitab Digital).

Al-Munawi, Syaikh Abd. Rouf. Faidhul Qodir. Maktabah Syamilah (Kitab Digital).

Al-Qurtubiy, Muhammad bin Ahmad Abu Abdilla. Tafsir al-Qurtubiy. Maktabah Syamilah (Kitab Digital).

Ar-Rozi, Abu Abdullah Muhammad Fakhruddin. Tafsir ar-Rozi. Maktabah Syamilah (Kitab Digital).

As-Shobuni, Muhammad Aly. Shofwah at-Tafsir li ash-Shobuni. Maktabah Syamilah (Kitab Digital).

Ath-thobary, Abu Jakfar Muhammad Bin Jarir. tafsir ath-Thobari. Maktabah Syamilah (Kitab Digital).

Ath-Thobroniy, Sulaiman bin Ahmad Abu al-Qosim. Mu'jam al-Kabir li athThobroniy. Maktabah Syamilah (Kitab Digital).

Hijaziy , Muhammad Mahmud. Tafsir al-Wadhih. Maktabah Syamilah (Kitab Digital) .

Hilmy, Mashdar. 13 Oktober 2018. Negeri di antara Dua Bencana. Harian Kompas.

Thanthowi, Dr. Muhammad Sayid. Tafsir al-Wasiith li al-Qur'an al-Karim. Maktabah Syamilah (Kitab Digital) .

www.kpk.go.id. diakses 26 Oktober 2018.

www.wikipedia.Org. diakses pada tanggal 13 Oktober 2018.

Yusuf, Abu Hayyan Muhammad bin. Tafsir al-Bahr al-Muhiit. Maktabah Syamilah (Kitab Digital). 
Jurnal Pendidikan dan Pranata Islam 